\title{
Tachadura. Reflexiones en torno a la artificialidad del dilbujo ${ }^{1}$
}

\section{Artículo de investigación}

\section{Jhon Felipe Benavides Narváez}

Universidad de Nariño

jhonfelipebenavides@gmail.com

Recibido: 20 de marzo de 2019

Aprobado: 25 de julio de 2019

Cómo citar este artículo: Benavides Narváez, Jhon Felipe (2019). Tachadura. Reflexiones en torno a la artificialidad del dibujo. Calle 14: revista de investigación en el campo del arte 15(28). pp.266-281. https://doi.org/10.14483/21450706.16265

Agradecimientos

A todos los creadores convocados en el texto, cuyo corazón y obra, permitieron la escritura.

A los dibujantes por venir.

\section{() (1)}

https://creativecommons.org/licenses/by/4.0/deed.es 


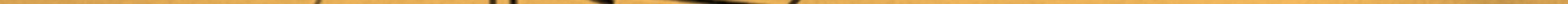




\title{
Resumen
}

El presente texto reflexiona sobre la tachadura como parte constitutiva del dibujo, y a la vez, sobre la exposición del dibujante a la artificialidad de su traza. Gracias a la revisión de la obra escritural y artística de diferentes creadores de Pasto, al suroccidente de Colombia, es posible proponer la tachadura como una concepción singular que sucede en esta ciudad. Abordando las problemáticas de representación de la grafía, su enseñanza, exposición y concepción, se entiende que los creadores sugeridos para esta exposición conceptual y vivencial — pese a su cercanía con lo académico- proponen los desbordes propios del dibujo al impedir que su traza se enclaustre en los linderos académicos.

\section{Palabras claves}

Tachadura; artificialidad; dibujo; traza; dibujante.

\section{Cross-out. Reflections on the Artificiality of Drawing}

\begin{abstract}
We reflect on crossing out as a constitutive part of drawing and, at the same time, on the exposure of one who draws to the artificiality of her own trace. Thanks to the revision of the written and artistic work of different creators of Pasto, in the southwest of Colombia, it is possible to propose the cross-out as a singular conceptual approach taking place in this city. Addressing the problems of representation surrounding tracing, its teaching, exposition and conception, it is understood that the creators that were suggested for this conceptual and experiential exhibition - despite their closeness to academia- propose the overflows typical of drawing by preventing its trace from becoming cloistered in academic boundaries.
\end{abstract}

\section{Keywords}

Cross-out; artificiality; drawing; trace; drafter.

Effacement. Réflexions sur l'artificialité du dessin

\section{Résumé}

Nous réfléchissons à l'effacement comme partie constitutive du dessin et, en même temps, à l'exposition de celui qui dessine à l'artificialité de sa propre trace. Grâce à la révision du travail écrit et artistique de différents créateurs de Pasto, dans le sud-ouest de la Colombie, il est possible de proposer l'effacement comme une approche conceptuelle singulière se déroulant dans cette ville. Abordant les problèmes de représentation du traçage, de son enseignement, de son exposition et de sa conception, il est entendu que les créateurs qui ont été proposés pour cette exposition conceptuelle et expérientielle - malgré sa proximité avec les universitaires proposent les débordements typiques du dessin en empêchant sa trace de se cloîtrer dans les frontières académiques.

\section{Mots clés}

Effacement ; facticité ; dessin ; trace ; dessinateur.

Rasura. Reflexões em torno da artificialidade do desenho.

\section{Resumo}

O presente texto reflete sobre a rasura como parte constitutiva do desenho, e, por sua vez, a exposição do desenhista à artificialidade de seu traço. Graças à revisão da obra escritural e artística de diferentes criadores de Pasto à sul-ocidente da Colômbia é possível propor a 
rasura como uma concepção singular que sucede nesta cidade. Abordando as problemáticas de representação da grafia, seu ensino, exposição e concepção se entende que os criadores sugeridos para esta exposição conceitual e vivencial- pese sua aproximação com o acadêmicopropõem os desbordes próprios do desenho ao impedir que seu traço se enclausure nos limites acadêmicos.

\section{Palavras chave}

Rasura; artificialidade; desenho; traço; desenhista.

\section{Maillallachiska}

Kai mailla kikapi parlakumi mailla mai kai llagta pasto sutimanda kawachispa kausaikun llakiikuna,sug iachaikudurkuna Munanaku allilla kawachingapa nukanchita ruraspa kilkaspa pangapi nunanaku ruranga allilla tukuimanda kangasin.

\section{Rimangapa Ministidukuna}

Mana allilla ruraska; runakuna ruraska; ruraikuna; kawachii runakuna ima nunaska; rurador. 
"Lo artístico consiste en tachar las letras o el dibujo" Román Ramírez (27/06/2012)

La tachadura hace parte del cuerpo dibujado. La densidad dada por el gesto ayuda a la presentación de su acontecimiento. Es a lo que asiste el dibujante de la ciudad de Pasto, a la superación de lo representativo del mundo porque ya no le es suficiente; para lo cual apela a la movilidad de una mano que no le pertenece o que cambia, con toda su naturaleza proteica acorde al movimiento singular de lo que diseña en forma de visibilidad. Esta visibilidad no asiste a lo ocular, a lo retiniano, a la secularización de lo sagrado. Se hace visible para hacer tolerable este mundo y lo otro, como si al ilustrar no solamente se dejara constatación de una mirada, sino la amenaza de su enceguecimiento por la fuerza con que llega la luminosidad de lo que no tiene luz. Superada la luminosidad artificial de la pintura (el esfumado y el claroscuro pictórico) ya la luz no se añade o simula que es parte del trazo, diseño y las líneas.

Dibujar se lo ha relacionado con esbozar un argumento, una idea, un planteamiento político o discursivo, pero, cuando este verbo hace cuerpo en ese inacabamiento sugerido como esbozo, se vuelve terrible desde su banalidad. Por eso, dibujar es asistir al preludio de acontecimientos, a la aparición sugestiva de lo monstruoso de lo que podría llamarse obra. Pero esta producción si se quiere relacionar con la poética de lo obrado- se consume a sí misma a partir de la tachadura; riesgo que sucede al desaparecer el dibujo por su propia saturación. Así lo habría caricaturizado el artista pastuso Javier Gómez al exponer en forma de plana escolar la palabra tachar (Imagen 1), acudiendo a una nostalgia escolar para evidenciar una palabra que siempre aparece en forma impositiva en el dibujante (quien lo asume también como un mandato). Insistencia por dibujar o dejarse atravesar por la línea es otra forma de ser afectado por lo lineal, inclusive sobre la idea constante de Gómez de abandonarla por haberla usado en demasía (al punto inclusive de permitirse obras cuya intervención sobre la materia sea mínima, restringida al hecho de mandar a otro, a un obrero su realización²). Por

\section{$1 \quad$ Este texto hace parte de la investigación Dibujo de Ciudad.} Trazas de lo inhumano en la ciudad de Pasto del doctorado en Antropología de la Universidad del Cauca en donde se expone el carácter in-humano del dibujante y su grafía en lo citadino.

2 Lyotard lo relaciona con una nueva tekné, donde el cálculo es imprescindible, como si todo el accionar tanto el que preside como la reacción esté sistemáticamente calculadas de antemano, afín a una sociedad industrial que calcula hasta las formas de distribución de su producto (inclusive si el tal producido no sea tan visiblemente supuesto, la imagen que se intitula Negación poética se toma como insulto al interior de un grupo de estudio sobre dibujo. Sin embargo, Gómez alude al riesgo de que la línea sea también negatividad en potencia de la obra. El dibujo pone en entredicho la hegemonía del Arte, siendo la base constructiva y pedagógica de su enseñanza, es a la vez la imposibilidad de reducirlo a ser un basamento educativo, inclusive desde su exhibición en los museos o galerías y en la inscripción en el mercado del arte local. Por su fragilidad (así me lo haría saber la guía del museo del Prado, al preguntar por los dibujos de Goya) y el hecho de su cercanía con la tachadura (y sus implicaciones del orden psíquico), exige otras formas de exhibición, que desbordan el carácter contemplativo del museo moderno y que se trasladan al profesor de Artes, asumiendo que el dibujo es un mero instrumento (inclusive de fe sobre lo contemporáneo)

reconocible bajo la autoría y contacto). Leamos: "Las obras producidas por la nueva tekné llevan necesariamente, en grados diversos, en sitios diversos de sí mismas, las huellas del hecho de que han sido determinadas por un(os) cálculo(s), sea en su constitución y/o restitución, sea únicamente en su difusión. Y por "cálculo" no entiendo sólo el que ocupa el tiempo de los ingenieros en informática, sino hasta la contabilidad inevitable de los espacios y tiempos, de todos los tiempos, incluidos los llamados 'de trabajo', empleados en la producción de esas obras y su difusión" (Lyotard, 1998: 114). Es evidente que el rechazo a dicha imagen era calculado desde su realización; inclusive los posibles quiebres (el comentario posterior, su inclusión en la afectación y emoción del dibujante sobre su discurso y obra). Pues al igual que cualquier celada, es un dispositivo funcional que inclusive prevé estas palabras signadas en este texto. ¿Será por eso que solemos bromear con algunos dibujantes sobre el parecido de los catálogos de las exhibiciones contemporáneas con anuncios de supermercados, de aquellas televentas que nos hacen creer la bondad de productos exóticos? Y entre risa y risa, hay una sentencia sobre la relación directa de lo contemporáneo con los procesos de producción y distribución del objeto industrial. La manufactura negada es remplazada por este terrible cálculo que está por encima de la matemática del creador (que siempre acompaña la realización de una obra). El artista asimila la totalización de la relación y la mirada frente al producto, poiesis excesivamente productora y funcional que pretende clausurar el acontecimiento. No obstante, el dibujo es un fallo, un error, una línea de más en dicho dispositivo técnico. Se anticipa a la calculadora. Ni siquiera el dibujo mecánico sugerido por Duchamp para anular el gusto puede ser mecánicamente ajustado a la lógica del cálculo, pues es una plana irregular, torcida, caligrafía ma llevada. Ahora es posible entender las propuestas, por ejemplo, del artista pastuso Alejandro Domínguez (Imagen 3) donde distorsiona el formato del cuaderno y desvía las líneas industriales sutilmente, quebrando esa cuadratura. Ahí, donde aparentemente no es posible la escritura, yace toda la posibilidad de la letra, pues en ese formato educacional el dibujo impulsa la línea hacia adelante. Insinuando una negación de lo académico también ironiza la tecnificación del dibujo bajo la perspectiva de la habilidad y la enseñanza. Si se ha querido colocar el mote de maldibujado, es también para darle posibilidad a la abyección de la obra, lo que resta, lo que se ha dejado, y en esa orfandad proponer una perspectiva sobre el dibujo. 
que se deja, máquina obsoleta, cuando ya ha cumplido una etapa de aprendizaje. Javier Gómez afirmaría que habría abandonado el dibujo pues para él seis meses fueron suficientes, haciendo énfasis en una obsesión por los objetos y sus detalles, y lejos de superar o ironizar la presencia excesiva del modelo, dejaría a un lado el dibujo como si fuese una etapa, un ciclo de aprendizaje, una materia superada. Ante este dictamen, ya la línea se le vuelve problema a sanar en sus obras y tendría su acento en toda una "acción perfomática" (como aludiría Javier 25/4/2013 a la fotografía del cuadernillo) de la configuración de dispositivos técnicos y tecnológicos. Abandonar el dibujo como si fuese una etapa de aprendizaje, es a la vez abandonar-se a la inmanencia de la traza. Inmundus, ausente de ornamentos pero también de materia (clausura al fin de cuentas del cosmos a partir de una justificación política) pese a que se prefigura como operación y que lo matérico se haga cuerpo en forma de blanqueamiento.
El blanqueamiento -esa obsesión material y conceptual de Gómez por el blanco quirúrgico del algodón o de materia blanqueada - acentúa la necesidad de la tachadura del dibujo. No ese acto físico que constantemente sucede en la pintura, sino ese acto de la traza que impulsa y expulsa lo grafico desde varios centros de desfocalización en el dibujo, en su realización y ó El abandono del dibujo se siente en la planimetría: ¿acaso no es notorio recordar por parte de los dibujantes que en primaria era un error la tachadura en los dibujos y que debía llenarse de color una figura preconcebida? ¿Acaso esos círculos en rojo del profesor de dibujo lineal en mis ejercicios no eran una marca de violencia oficial sobre la perspectiva que intentaba corregir bajo su óptica personal? Recuérdese que no había mayor ejercicio de violencia que el del docente al tachar los errores en la tarea escolar, inclusive en los dibujos de la academia de arte, a cuya negación y sentencia le es eficaz la tachadura profesoral (inclusive desde
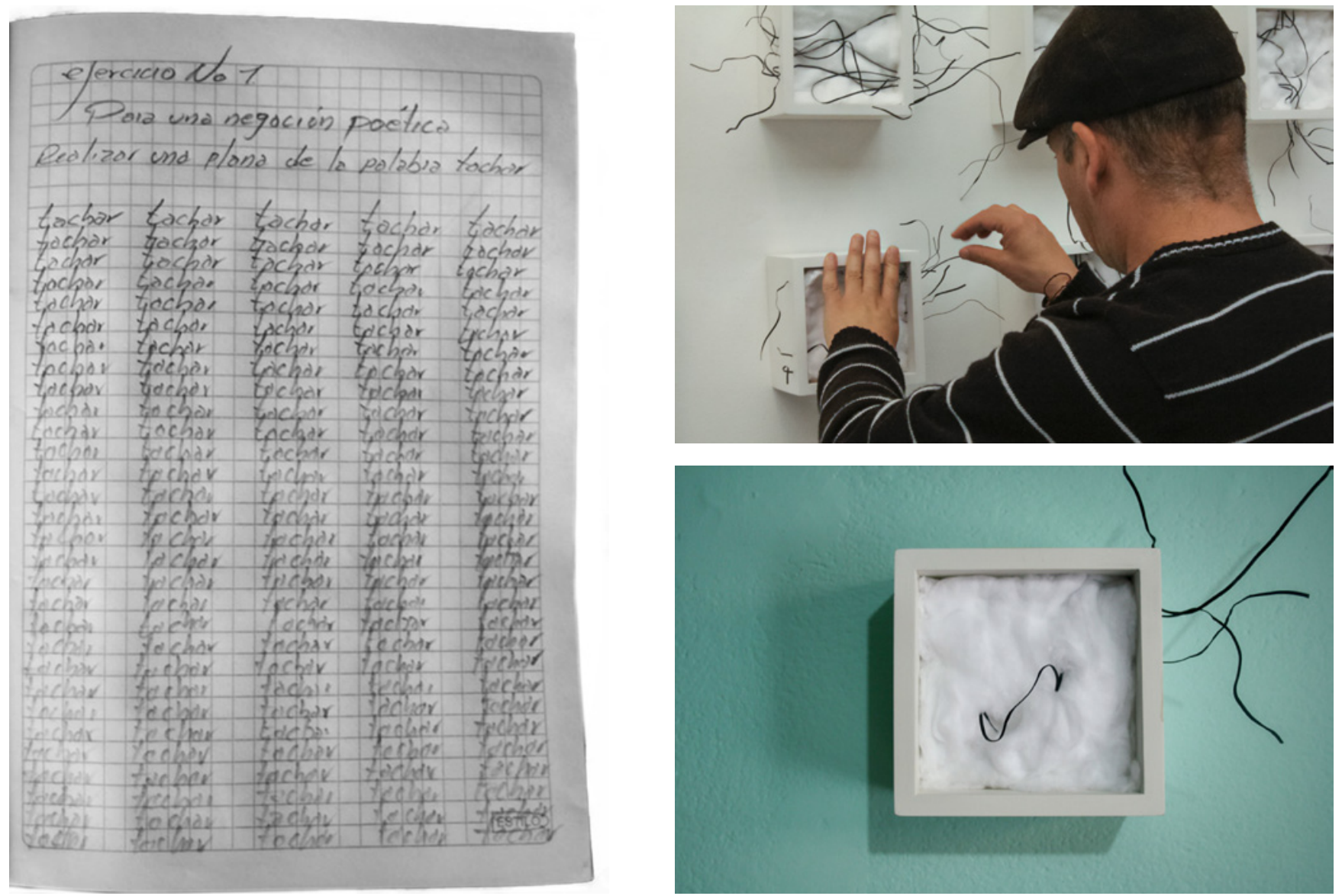

Imagen 1. Javier Gómez. Izquierda: Ejercicio No.1 Para una negación poética /Fotografía de cuaderno/Imagen presentada al grupo de dibujo Monstruo Infante /2013. Derecha superior: Imagen de Javier Gómez montando su obra en la exposición Monstruo Infante. Pasto, Centro Cultural Palatino. Abril 17 de 2012. / Derecha inferior: Imagen de una de las 24 piezas de la obra presentada a la exposición Monstruo Infante. Pasto, Centro Cultural Palatino. 2012 


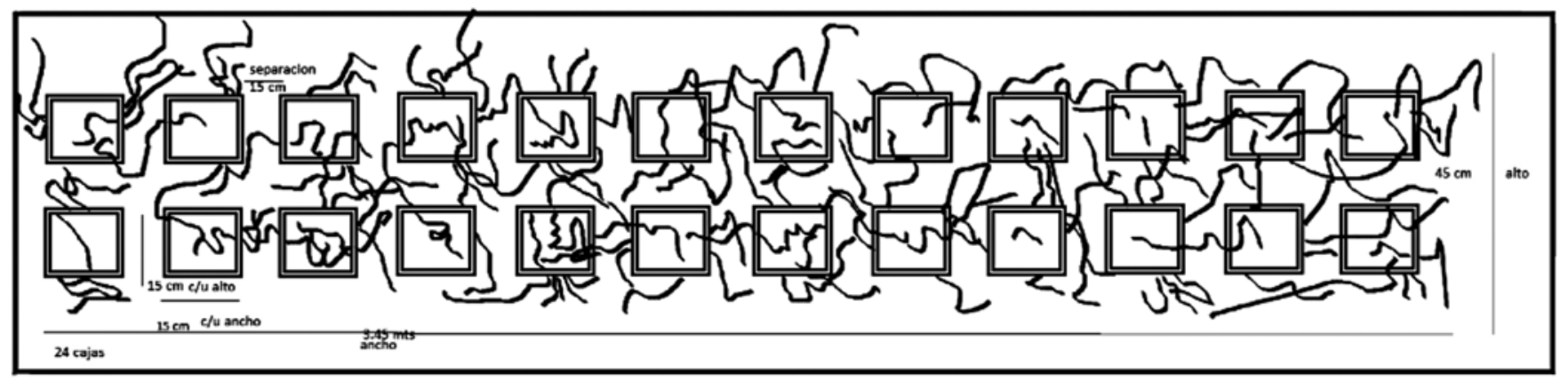

Imagen 2. Javier Gómez. Plano montaje. Exposición Monstruo Infante. Centro Cultural Palatino- Facultad de Artes (Universidad de Nariño). Pasto, 2012.
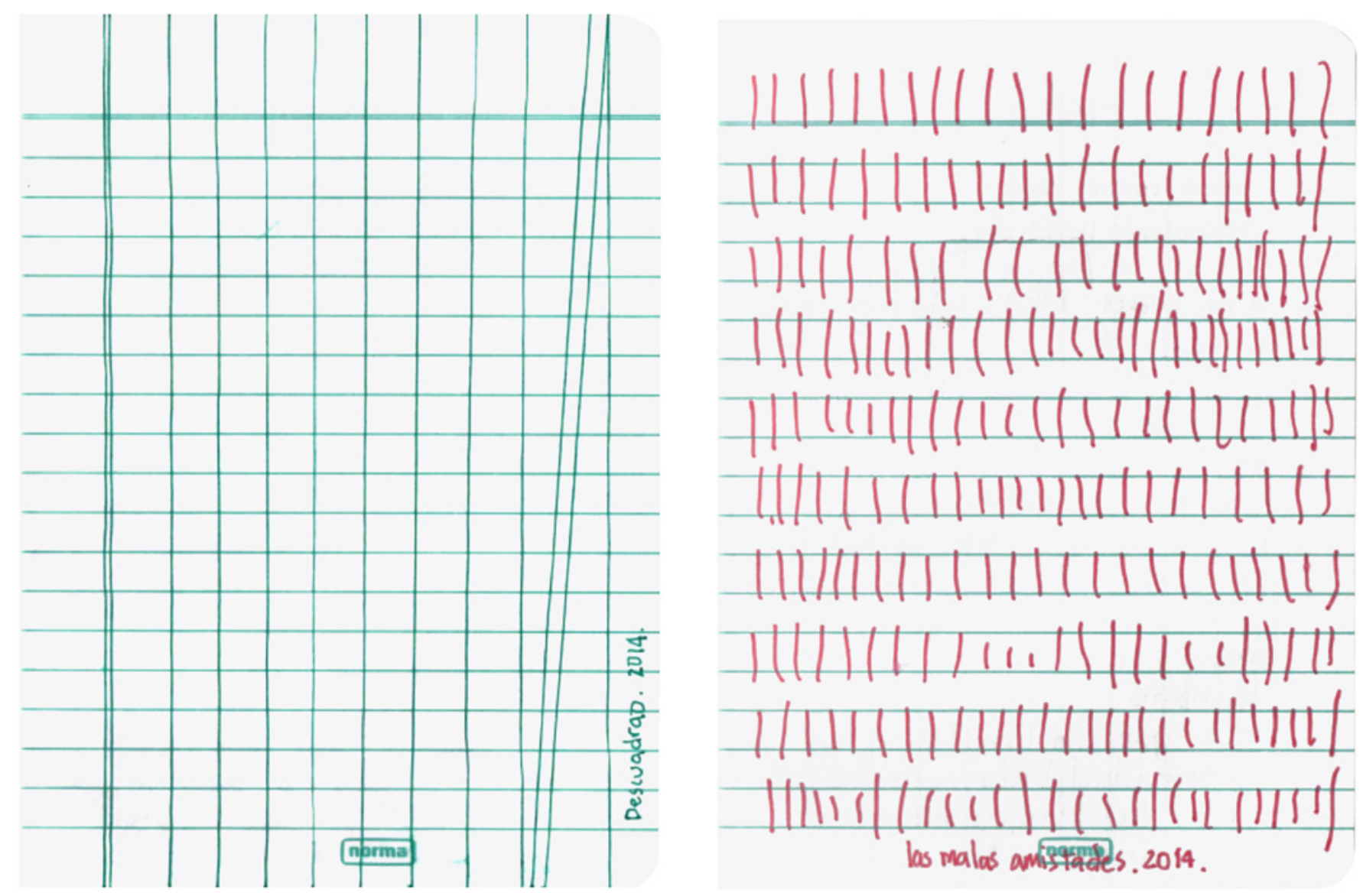

Imagen 3. Alejandro Domínguez. Izq.: Descuadrado. Dibujo sobre formato de cuaderno, 2014/ Der.: Las malas amistades. Dibujo sobre formato de cuaderno, 2014. De la serie Los presto dibujos. Colección de marcas para pasar el rato. 2014. 
la simulación de la plana escolar, intento fallido de infantilizar el discurso de los dibujantes). No obstante, tachar es desconocerse en el dibujo, inclusive desde el juego de tomar como referente las cosas personales, la mirada y el rostro. No es un mero ejercicio para solventar la coordinación visomanual en la que se insiste desde los centros educativos. Es dislocación del cuerpo del artista que se evidencia en una firma que atraviesa el gesto, otro cuerpo que ha sido y exige ser atravesado por diversas corporeidades que siempre le son ajenas al dibujante, cuyo ejercicio requiere una concepción diaria y continúa para hacer desplazar la traza a diversas dimensiones fuera y dentro del campo de acción de lo dibujado haciendo que el artista no esté presente para ser identificado.

A propósito de esta dislocación del cuerpo, Derrida se refiere al cuerpo de Van Gogh en este sentido, a una violencia de no estar presente el artista, leamos: " que el cuerpo mismo de Van Gogh que impregna sus obras está lo más violentamente implicado e inserto en el momento de pintar porque no está presente durante el acto, porque el cuerpo mismo se escinde o, digamos, se rompe por la no presencia, por la imposibilidad de identificarse consigo mismo, de ser simplemente Van Gogh" (1994, p. 13). Entiéndase también como forma de violencia más compleja que la fantasía escolar de tachadura sugerida por Gómez.

En 1960, Joan Miró (Imagen 4) mandó a copiar un autorretrato realizado en 1937. En esta copia sobrepuso una línea negra como otro rostro sobre su representación anterior, además de unos círculos en colores emblemáticos de su composición visual, que en apariencia maltratan a tal punto la composición anterior que se antepone como una enrostración nueva, para dar comienzo a una serie de diversas composiciones que distan de las primeras ilustraciones y búsquedas del dibujante catalán. Pero, y teniendo presente que es una búsqueda pictográfica, podemos ver la fuerza compositiva de la tachadura como forma de rostro que anticipa cualquier anulación, ejercida desde la academia de arte o desde la ciudad que violenta toda mirada de frente al otro. El rostro del pintor ya no es un elemento identitario ni siquiera de una etapa de construcción estética pues al ser tachado por otra gestualidad más gruesa, más directa, digamos menos ilustrativa, hace aparecer el rostrum, filón y filo de bestialidad en la traza.

No obstante, hay un carácter artificial en la línea que yace en el dibujo. Artificialidad y domesticación que Javier Gómez dimensiona desde una linealidad dada desde un cable maleable (Imagen 1). En la exposición itinerante Monstruo Infante ${ }^{3}$ (2012) dedicada a diferentes perspectivas sobre el dibujo, exhibió una serie de cubos blancos que contenían, a manera de simulación, unas líneas estratégicamente colocadas en algodón. El alambre negro junto a su colchón en blanco daba la sensación de aquellas tareas escolares donde veíamos crecer - tal cual magia- el tronco al frijol después de someterlo a un baño de alcohol. No en vano, Javier, siguiendo esta idea, ha untado formol a las cajas uniformes que se disponen en una cuadricula solamente quebrada por las líneas negras que están dispuestas de acuerdo a un plano de montaje previo (ver figura 2). Ironizando el hecho casi mágico y artificial del crecimiento de la planta, nos acerca a algo oscuro y entrañable: al mal que anida en la traza, como si en el fondo, y pensando en los principios de una generación espontánea, todo puede ser simulado, inclusive la eclosión de vida y la movilidad lineal de lo natural. El formol intenta petrificar en un estado latente a la artificialidad de la línea, no obstante, la movilidad de la línea, su desplazamiento se da inclusive más allá

3 En 2011, el artista visual Alfredo Villarreal me invitó a organizar un taller de escritura cuya sede sería la librería Kevin (ahora Orión), la cual dirige desde hace algunos años. Al exponerle mi agotamiento de dichos talleres le propuse formar un grupo de dibujantes que en principio pudieran tener un espacio de confrontación de su obra y de discusión.Así se fundó Monstruo Infante, cuyo nombre fue una suerte de azar entre palabras que resonaban entre los invitados, al calor de unos hervidos (esas portentosas bebidas de fruta y aguardiente casero). Lo interesante de dicho grupo fue exponer las diferentes perspectivas sobre el dibujo más allá de las antipatías muy propias de nuestro oficio. La exposición itinerante que surgió de dicho grupo permitió confrontar los diversos matices y perspectivas de los dibujantes de la región con otros de Colombia y el extranjero, y pese a sus dificultades de organización y la curaduría abierta a más no poder a una generosidad carnavalesca (a medida que circulaba la exposición se unían más expositores), esta exposición debe ser considerada para la historicidad del suroccidente colombiano, pues miremos quienes expusieron y dan cuenta con sus nombres, de ser una exhibición re-presentativa del dibujo y sus posibles exergos: Adrián Montenegro, Óscar Aguirre, Jhon Benavides, Jorge White, Alfredo Villarreal, Javier Gómez, Román Ramírez, Juan España, Óscar Salazar, Bruno Mazzoldi, Álvaro Pantoja, Fercho Yela, Jhon Cortés, Hanna Ramone (Johana Martínez), Ángela Barrera, Santiago Benavides, Julían Yela, Fernando Guerrero, Vivian Pantoja, Juan Pablo García, Mario Bastidas, Jesús Holmes Muñoz, Paulo Bernal, Roberto Bastidas, Juan Granda, Milton Cabrera, Jhon del Castillo, Gustavo Benítez, Cristian Bastidas, Giraldo Gómez, Catalina Yela, Boris Arteaga, Lenin Cañar, Alfonso Espada, Rosa Tisoy, Luis Vázquez, Julián Moreno, Jennys Obando, Natalia Pipicano, Rodrigo Orozco, Mario Álvarez y Dubel Reina. Junto a ellos: Luisa Roa, Atsuo Nakagawa, Alex Chiu, No para Innita, Naohiro Kawakawi, Jazz Buitrón, Eduardo Taborda y Antoni Miró. De ahí que sea tan importante la obra de Javier Gómez, pues dispone su perspectiva al cruce de diversos dibujantes, a diversas acciones de tachadura si es que no de simpatías y antipatías. 

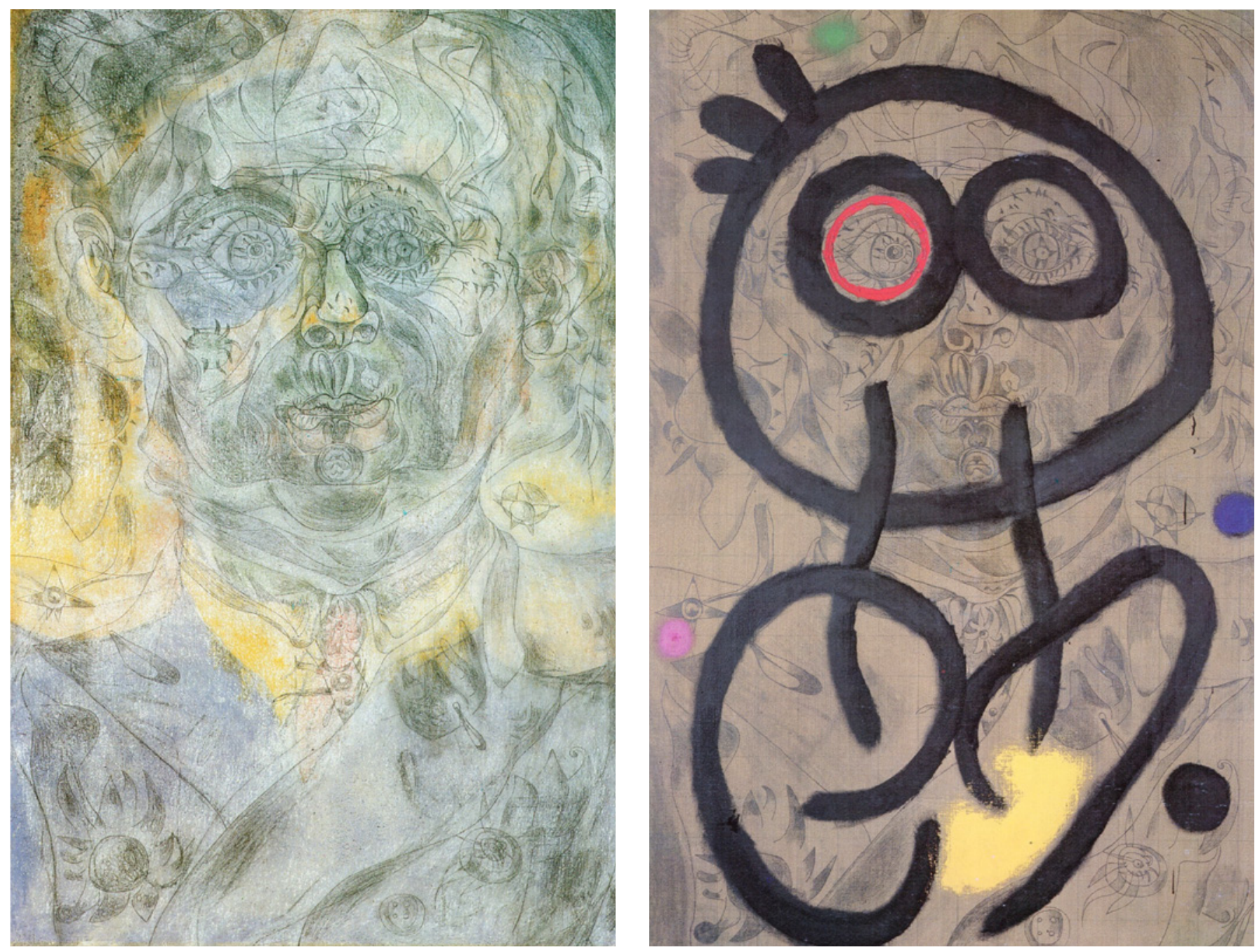

Imagen 4. Joan Miró. Izq: Autorretrato I, Lápiz y óleo sobre tela, 1937/38. Der: Autorretrato, Oleo y lápiz sobre tela, 1960. Imágenes extraídas del libro Miró de Walter Erber (Erber, 1992, pág. 85 y 139)

del control del autor-instalador, pues dejó en manos de dibujantes sus posteriores montajes. El cálculo en el dibujo (inclusive cuando esté es asumido desde otros formatos) no es posible, ni mucho menos, desde una matemática cartesiana. Las cajas que se disponían como una categorización de un desván científico, en algunos casos, como tumbas abiertas, se desubicaron, ya no eran parte de la escenificación inicial y terminaron en el suelo (en algunos casos como en la exhibición en Bogotá), o reducidas en tamaño por disposiciones de espacio en Ipiales o Popayán. Las pequeñas tumbas yacen fuera de su lugar inicial, abandonadas, maltratadas por el equívoco dibujante y lo que inicialmente era una escenificación científica de un fenómeno comprobado, terminaron por ser desplazadas a tal punto que esos cubos están en diferentes casas, soportando la acción intempestiva del hogar, a veces sometidas a una disfuncionalidad decorativa. Yacen en demasía por su propia domesticación, y aun así, la línea del dibujo sigue desplazándose hacia la domus en forma de florescencia (desde el plano del montaje, innegable y bello dibujo, ya se anuncia esto). Entonces, ahí donde se intuye una enfermedad o artificialidad del dibujo, se antepone su conjuro a partir del exceso de lo figurativo al realizar un dibujo pensando en su tachadura.

Así mismo, se pueden entender las composiciones realizadas por el artista visual Adrián Montenegro (figura 5). Al alterar la disposición de los cables eléctricos desparramados por la ciudad de Pasto, les da otra naturaleza: la pictografía de un cuerpo naciente, pues la artificialidad también provoca la vida y es con el dibujo, al menos con la alteración de la linealidad del cableado, que se puede sentir esto. Y estas líneas que a ojos de urbanista son molestas, se tuercen a favor de una corporeidad que está ahí, latente en ellos. Inclusive formando una simpatía animalesca con los seres: un pájaro forma el ombligo de estas figuras levemente soportadas 
por el fondo grisáceo de las nubes pastusas. Entonces, la línea-cable es a la vez su propia figuración, una torsión que favorece la aparición del otro, inclusive como formas de acumulación de pelo en esta corporeidad artificial del cable eléctrico. Pero no es un ejercicio neumático, como quiere llamarse al insuflar de espíritu al cableado visiblemente expuesto en las calles pastusas (pues en estos dibujos los cables lo siguen siendo) sino sugerir la aparición de lo otro. En esta inversión de la imagen de lo artificial, se cuestiona su permanencia en la ciudad pues no se prefigura la petrificación de la imagen, digamos fragiliza la linealidad al acrecentar la artificialidad de la línea, entendiendo que hay algo en la línea que impulsa a su animalidad y lo hace a partir del otro debido a que es el dibujante quien se permite este juego inclusive desde la disposición de la alteración digital de lo fotográfico. Entonces, el dibujo no prevé la domesticación de lo lineal ni su aparición; es por eso que siempre apela a otro dibujo, tachadura y desplazamiento que sucede a veces a manos de otro dibujante.
Sobre una obra (Imagen 6) que preferí abandonar por cuestiones estéticas y de sigilo, el artista Paulo Bernal diseñó encima de mis personajes otro rostro que identificó como un santo. En principio, quise dibujar una composición basada en una segunda versión de san Mateo de Caravaggio (San Mateo y el ángel, de 1602, cuadro que se encuentra en el altar de la Capilla Contarelli- Roma), pues en su primera versión la disposición de la mano del ángel sobre el evangelista, fue catalogada de demasiado familiar y la del santo de demasiado vulgar.Ese roce sutil ejercido en su segunda versión —donde todo el tacto sucede en el ángel, digamos en el cuerpo mismo de la anunciación- es lo que intentaba al diseñarlo como algo bestial que hacía vomitar a manera de sanación al santo escritor. En cambio, Bernal sin previo permiso, con la sutil violencia de quien se ve atraído por una imagen, encima del personaje que había sugerido el dibujo, ha ejercido su tachadura en y con este rostro (el cual habría de sugerirle tiempo después que era San Lucas, el santo
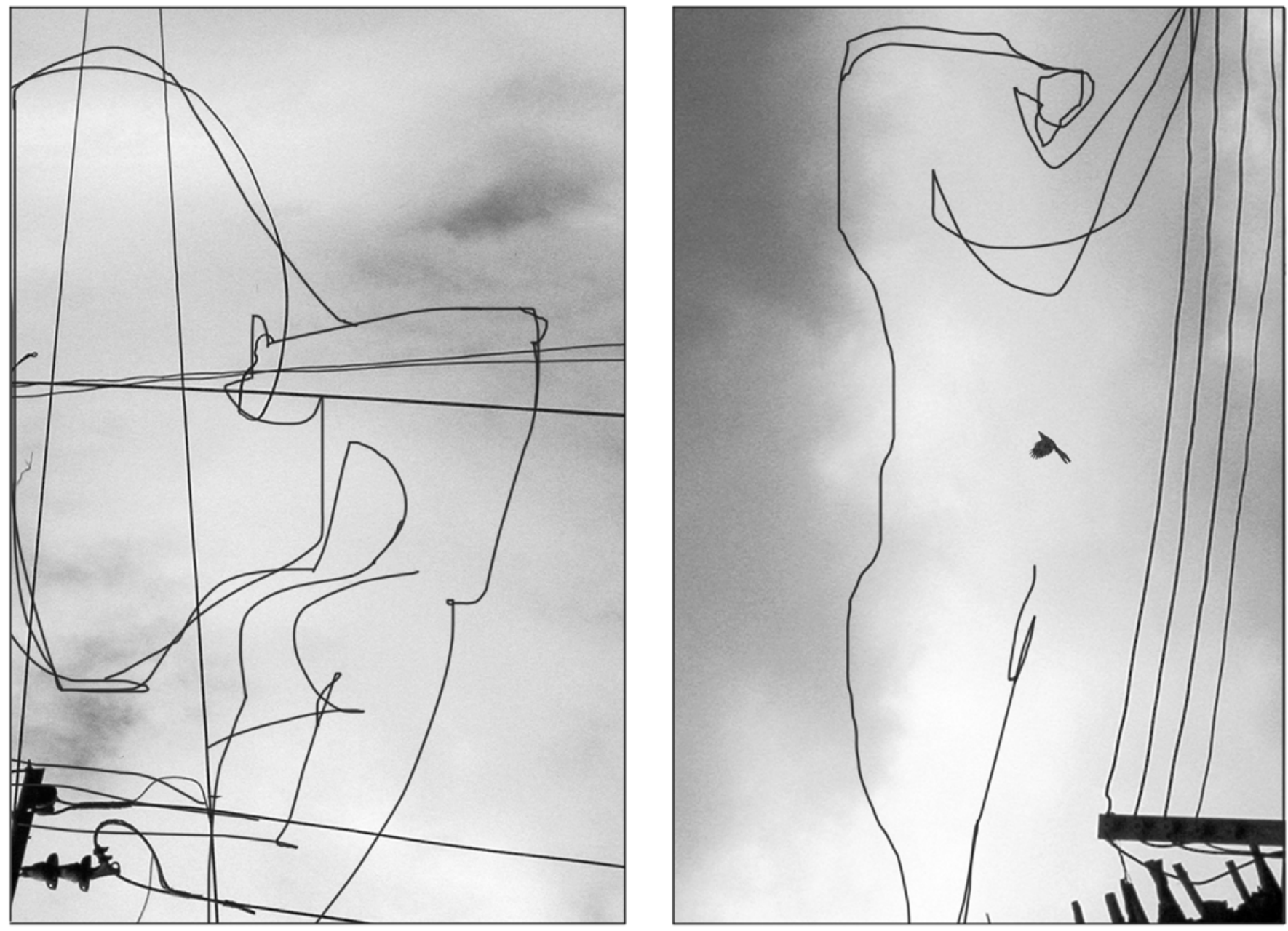

Imagen 5. Adrián Montenegro. Dibujo cables. Fotografía e intervención digital, 2008. 
pintor). Sendas trazas de grasa -la corrosiva manera en que el óleo pastel atraviesa el soporte a manera de líneas carnosas - diseñan el otro rostro tachando el anterior, pero también, alzando otro rostro que se evidencia en este otro dibujo. Entre estos tonos de carne (reflejos azules y naranjas) una línea negra de marcador sugiere una carga que se acentúa en el rostro a partir de un continuum lineal que va desde el cuello, atraviesa las fosas nasales, las órbitas, el entrecejo, todo el contorno de la cara para acentuar el vómito que sale del personaje.Y lo que en principio quería sugerir como el tacto de lo otro por una especie de ángel animal con cabeza de conejo - derrière de la otredad que viene de lejos- Bernal lo ha acentuado sobre una bestialidad que está precisamente en el rostro marcado de este Santo. Por un lado, persistencias de rostrocidad a las que los dibujantes suelen recurrir al asumir la ilustración de la ciudad, y que, en mi caso, son permeados por la animalidad que atraviesa lo urbano y en el caso de Bernal, por la santidad de lo bestial que se acrecienta por las líneas negras que soportan el peso de la mirada, la risa, la gestualidad de dolor y la carne. Por otro lado, tachadura como para prescindir de identificaciones del autor, pues al asumir la tacha es a otra voz que se sigue, a otro ritmo, pues no es la violencia eficaz del dictamen del otro, es que el cuerpo dislocado del dibujante es a la vez su propia voz y dibujo de esta violentación diaria.

La tachadura es un desplazamiento que se hace en el dibujo propio y no propio. No existen correcciones ni realces, físicamente expone el espaciamiento de las líneas, la movilidad del ductus "ese trazo idiomático por el cual se reconoce un dibujante incluso antes de que firme con su nombre" (Derrida, 2001, p. 205) y la fragilidad de lo anatómico frente a la letra; en algunos casos, evidencia el carácter nocturnal de una experiencia que se realiza a diario. Es así que el dibujante pastuso Andrés Ocaña haría tachadura con varios dibujos míos (Imagen 7). Siguiendo otro camino, digamos respondiendo a otra violencia gráfica, también expondría la desnudez de mi traza a partir de sendas líneas, colores, brumas y tonalidades que acrecientan la crudeza de mi dibujo. Partiendo de un ejercicio planteado para diseminar el autor a partir de un texto poético, los dibujos son abordados pensando en la tachadura de los mismo inclusive realzando la bestialidad del instante que suele aparecer en los apuntes del cuaderno del dibujante. Los cuerpos que en principio constituyen un juego compositivo sustentado en diagonales y cruce de tramas (el cuaderno por sus características de apunte no permite más que una distribución anatómica dada por los vértices y diagonales) son atravesados por la tachadura digital de Ocaña. Sea pensada desde la intervención quirúrgica del espacio por la máquina o por la introducción de letras-seres, lo que vemos es un inverso positivo de mi dibujo y a la vez su envés nocturno (ha nombrado a este dibujo con el nombre sugestivo de “El otro es un concepto demasiado abstracto"). Entonces, tachar también le permite presentar la doble imagen, trayendo y retrotrayendo hacia un cromatismo nocturnal, la línea abierta. Los recorridos de dicha intervención, no solo se conforman con la anatomía de los personajes, sino de los espacios e, igual como le sucede a Joan Miró con sus apropiaciones de los cuadros holandeses (por ejemplo la obra Interior Holandés de 1928 basada en el Tañedor de Laúd de Hendrick Martensz Sorgh (Erber, 1992, pp. 50 y 51), hace aparecer seres que anidan, parasitan, se acurrucan entre los espacios del dibujo. Para luego, exponer-se como dibujante en la temporalidad y suspensión de la eficacia gráfica. Entonces, la tachadura desplaza inclusive la idea inicial de intervención e ilustración, pues el poema ha sido diseminado en forma de grafías equívocas (pese a que Ocaña insiste en el dibujo como acción inequívoca). El dibujo conserva - a manera de vestigio fecundo- una traza antigua (cruda si se quiere) desprovista de ritual, en el borde de lo inhumano, pero que se hace obra en sí del lado de la historicidad del arte; no obstante, no remite a ningún autor de forma inmediata, se sostiene por fuerzas de resistencia e irrepetibilidad. Pues, como asevera Blanchot: "La obra de arte no remite inmediatamente a alguien que la habría hecho. Cuando ignoramos todo de las circunstancias que la han preparado, de la historia de su creación y hasta el nombre de quien la hizo posible, entonces la obra se acerca a sí misma" (1992, p. 209). Ocaña habría previsto esto, al seguir de cerca la forma como se aglutinan las líneas de mi dibujo. No obstante, se puede simular su reproducción a partir de las máquinas reproductivas (scanner y fotografía en este caso) las cuales abren los espacios interlineales que sostienen la supuesta originalidad del dibujante.

Por lo anterior, el dibujante no intenta reconstruir una memoria, propone una serie de dispositivos mnemotécnicos para la traza. Las formas que resultan de esto son "cristalizaciones del tiempo. No tiempo medido sino vivido y viviente" (como sugiere Octavio Paz (2004, p. 280) a propósito de los dibujos de Valerio Adami). Digamos, en una fila típica de lo ciudad de Pasto, el dibujante expone su propio ensombrecimiento y no la exaltación dramática de vivir en la ciudad, ni mucho menos cierta habilidad gráfica. Si este tipo de imposiciones se entienden como parte del tiempo laboral, 


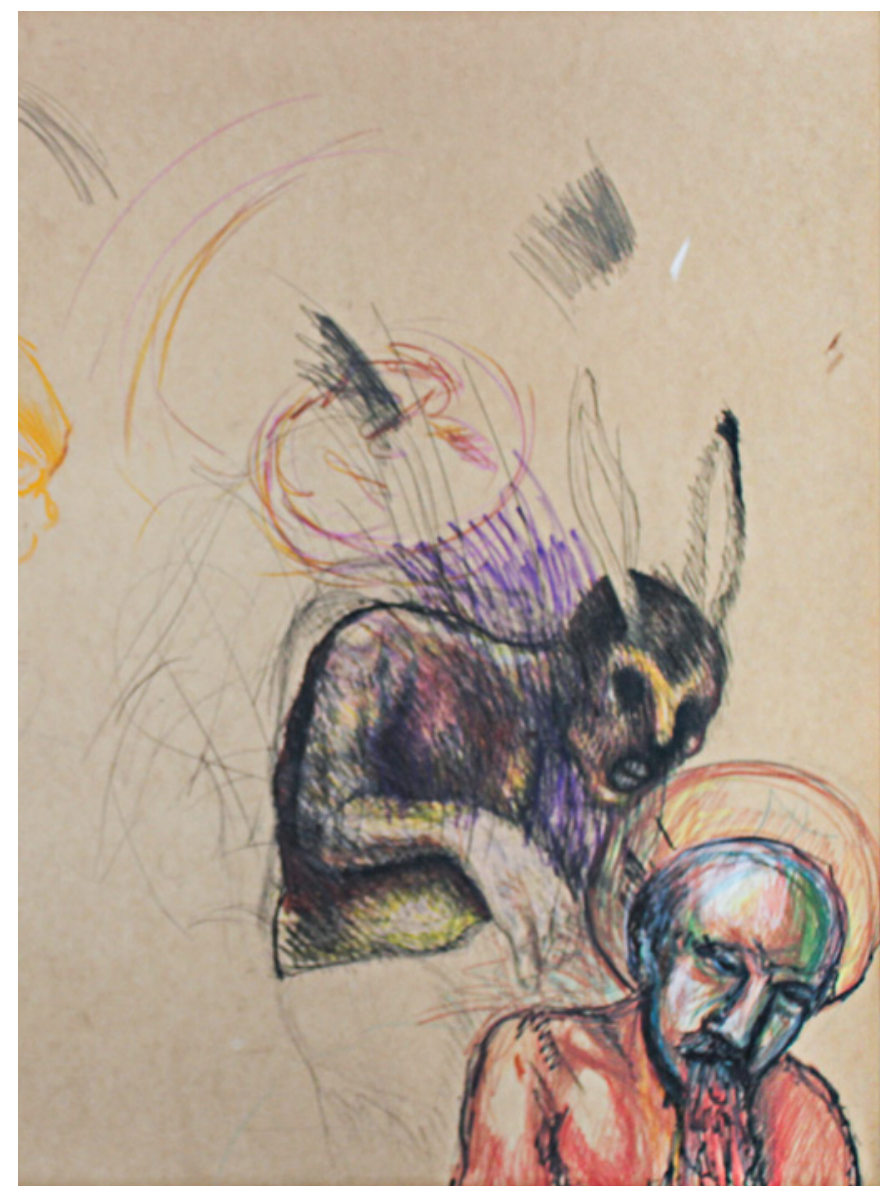

Imagen 6. JB (sup. izq.) y Paulo Bernal (inf. der.). Sin título. Lápiz color, marcadores y óleo pastel sobre mdf, 2013
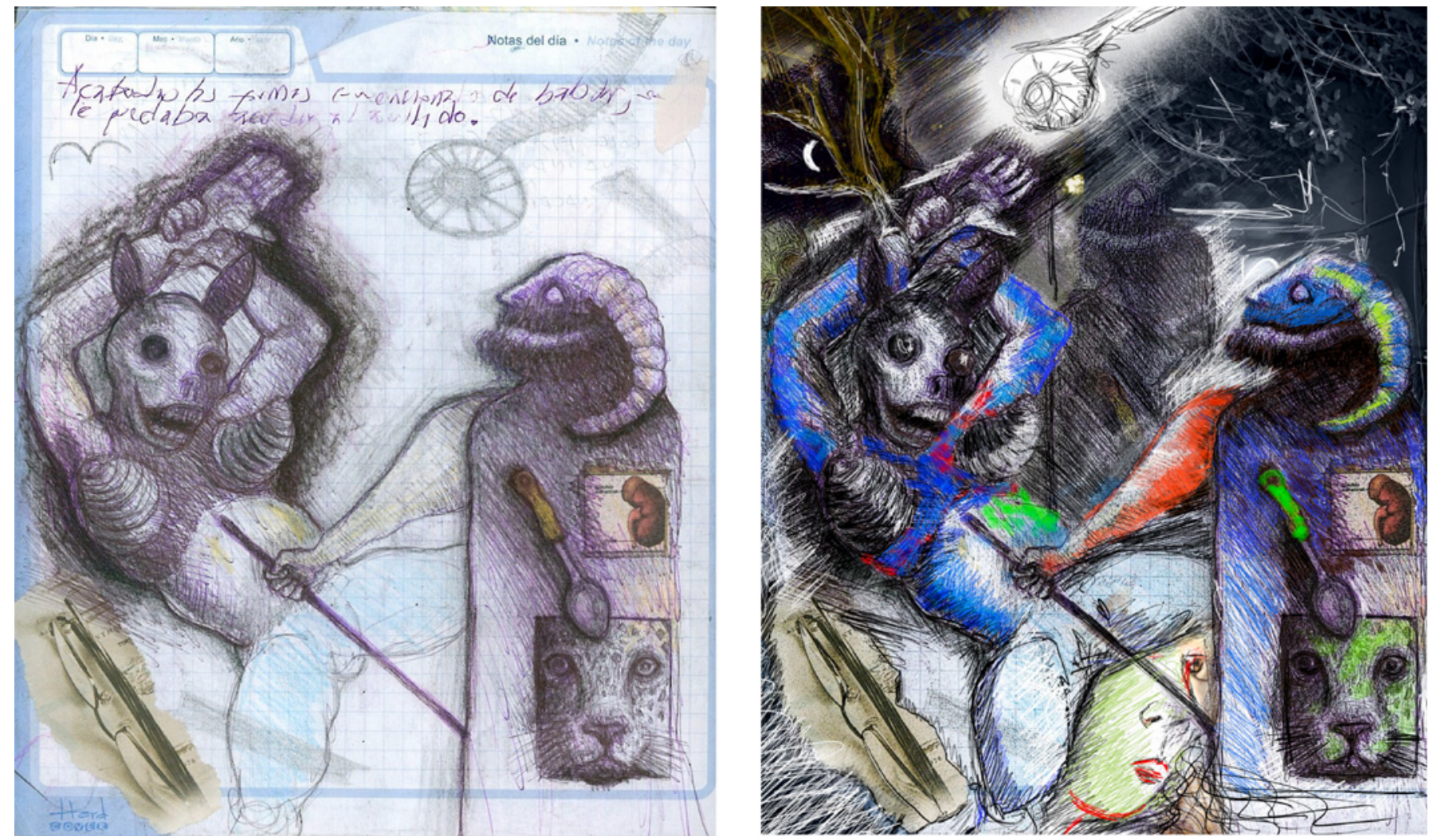

Imagen 7. Izq JB . Lapicero, carboncillo y collage sobre papel. Der.: Andrés Ocaña, intervención digital. El otro es un concepto demasiado abstracto, De la serie Intermedio Civilización Iluminada/2013 
dibujar estas escenas sería exponer de más la tachadura del dibujo, pues no son "retratos sino emblemas de los enigmas sucesivos y dispares que inventa el tiempo" (Paz, 2004, p. 280). Al dibujar una escena a las afueras de un cajero automático (Imagen 7) intuyo esta naturaleza del dibujo y su tensión con lo cotidiano. Al escenificar la angustiosa espera (siempre son escenificaciones lo que sucede con mis dibujos), diseñé el peso del bolso de una amiga -aferrado a ella como un insecto-y lo relacioné con el pedazo de un billete de mil pesos cuya otra mitad jamás encontré. Y entre lo que parece un apunte muy propio de urban sketcher (ilustrador de lugares visitados, sin que sea una actividad exclusiva de estos tiempos, se vuelve común por la facilidad del dibujante de volverse turista), surgen otros seres: una mujer acostada cuyo peso está en sus zapatillas, un personaje sentado que sostiene una máscara sonriente (al estilo emoticón) que había contemplado en otro lugar, la aparición monstruosa de un personaje encerrado (imagen que me asalta constantemente al mirar las ventanas enrejadas sean de Pasto o Popayán) y Jorge E. Gaitán que ahora hace parte de esta obligada temporalidad. El tiempo me obliga a dibujar, y lo que empieza por ser una imagen propia del estudio diario, si acaso de mirar a lo lejos a la impaciente amiga, se vuelve imparable, equívoca, atravesada por incontenibles líneas y vacíos en ocre que incrementan el peso inicial que quise ilustrar. Existe un maltrato y trato con esta imagen tan cotidiana, tan llena de esta temporalidad cíclica y laboral de la ciudad, pero que a la vez se vuelve también cuerpo y luz de la línea. Y esta línea que no puede ser continua se transforma en erráticas rayas que incremento como manera de acercarme al peso de lo inhumano que arrastra esta equivoca aparición. Deleuze habría concebido el maltrato desde la idea de lo cómico, pensando en que al realizarlo se violenta al cliché de la normatividad clásica, digamos, en nuestro caso del dibujo bien realizado bajo cánones de figuratividad bien extendidos en Pasto.Así narra la experiencia de Cezanne, con respecto a lo anterior: "Si Cezanne hubiese consentido en aceptar su propio cliché barroco, su dibujo habría estado perfectamente bien según las normas clásicas, y no habría encontrado nada crítico que decir. Pero cuando su dibujo era bueno según las normas clásicas, parecía un Cezanne completamente malo. Era un cliché. Se lanzaba entonces sobre él, extirpaba la forma y el contenido, después, cuando había devenido malo a fuerza de ser maltratado, agotado, lo dejaba tal cual, tristemente, pues no siempre era lo que quería" (2002, p. 51). Pero para hacerlo, para agotar al máximo todo cliché como asevera Deleuze y como parte del ejercicio del dibujante, es necesario

entender la alteración sobre su cuerpo, dibujarla, hacer del cuerpo tachadura.

Veo la tachadura en mi propia mano, cruce incesante de líneas en esta improbable herramienta de dibujante (demasiado pequeña y suave para alguien que ha hecho de lo manual su vida). Ahí, en el brotar de líneas, en el enrarecimiento de la lectura quiromántica, es un dibujo que brota en mi mano como una aparición. Para entenderlo, es necesario mirarla como centro de des-focalización del cuerpo del dibujante. Lo dimensiono al ver dibujar al artista pastuso Román Ramírez quién, al encorvarse, logra un equilibrio entre el brazo y el pecho, donde se deja entrever la sensación de dolor que ha convertido en postura para la aparición de sus líneas. Para soportar dicha movilidad -imagen de autonomía y desborde del cuerpo dibujante- realicé una ilustración de que da cuenta sobre este tiempo (Imagen 9), pues al presentar un retrato de Román lo que hice fue una serie de imágenes y una disposición circense alrededor de la figura de este formidable dibujante. Habría una necesidad de 
realizar un maltrato sobre un formato, para lo cual me había apropiado con anterioridad de una libreta de textos de un ejercicio de Mauricio Genoy, artista residente en la ciudad de Pasto, cuyos textos daban cuenta de las diferentes extracciones realizadas a otros artistas a partir de la idea del bus urbano: llevando consigo un pequeño carrito, Mauricio iba extrayendo, abstrayendo o robando imágenes y objetos de las obras de los demás creadores en un ejercicio académico a lo largo de la ciudad. El cuaderno, cuyas narrativas las dividió en diversas rutas, es lo que me permitió el ejercicio de tachadura sobre su caligrafía, realzando aún más la presencia de su traza, pero ejerciendo al igual que él, una apropiación. El nombre de su libreta no podría ser más oportuno para dicho traslado: Una metáfora contada desde lo más profundo de mi ser (2009), y entre caligrafía y caligrafía hacía hincapié sobre las afectaciones orgánicas y sensibles de las obras ajenas. En la misma libreta, el dibujante pastuso Fernando Yela, había realizado un dibujo imitando a mis personajes: un monstruo enmascarado al que al parecer solo le es posible ser una cabeza. Sobre estas prefiguraciones y algunos apuntes de direcciones, teléfonos y palabras, lancé el rostro del amigo dibujante, pensando en su traza, y veía o sentía más bien, que Román al dibujar parecía abrir su vientre con el lápiz como una apertura a lo que era posible solamente por la movilidad de su cuerpo. Jhon Berger siente lo mismo al describir lo que sucede en el cuerpo del dibujante: "los gestos parten de la mano, de la muñeca, del brazo, del hombro, posiblemente también de los músculos del cuello; los trazos que hace en el papel, sin embargo, siguen unas corrientes de energía que no son físicamente suyas y que solo se hacen visibles cuando las dibuja" (Berger: 2011, 20). Con estas afectaciones, estos dispositivos de líneas, configuraciones de anatomías animalescas, lo que intentaba es de-signar este dolor de parto, muy de santo contemporáneo, como apertura a sus animalidades (heridas impropias, cromatismos enrojecidos por el calor de su dibujo, sombras mediadas por presencias y no proyecciones).

Lo que se podría concebir como un palimpsesto del dibujo, es lo que se manifiesta como una azotada de transversales para darle un vibrato particular.Ya la luz no llega ni brota, es parte del personaje.Esta evidencia, esta manera de manejar la luminosidad de lo umbroso es lo que se presiente como forma de observancia de lo urbano. Así los ejercicios en la ciudad tienen la gracia de la tachadura del dibujante, por eso la arquitectura, lo humano y la luz se vuelven mancha y signo. Es una profanación del lugar del trabajo de quien abandona toda maestranza para retratar al otro. No obstante, no es un ejercicio ilustrativo, el retrato se hace así mismo.

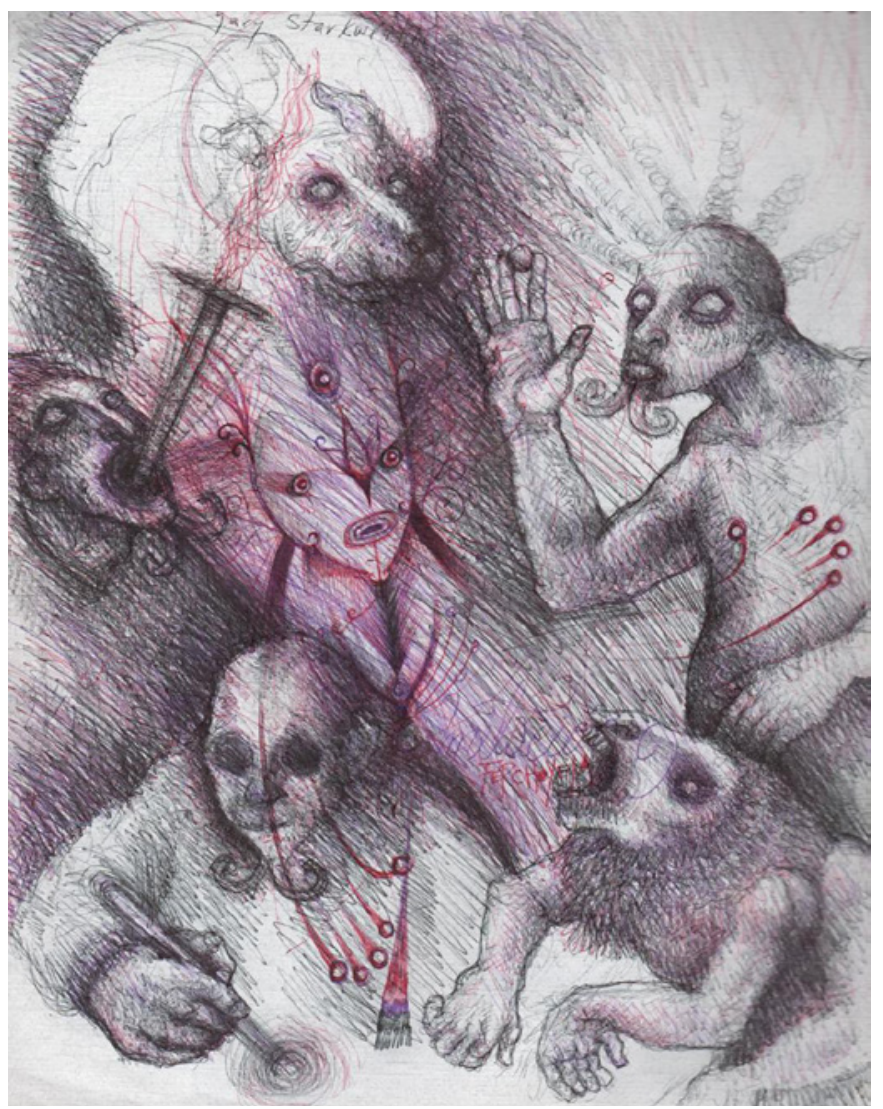

Imagen 9. Sin título. Retrato de Román Ramírez (parte inferior izquierda). Lapicero sobre papel lino (intervenido anteriormente con caligrafía de Mauricio Genoy y dibujo de Fernando Yela), 2013.

Solamente es posible volverlo carnosidad en el gesto o en el cuerpo sometido a la mancha. Por más que se intente volver a prefigurar los rostros, la línea desvía la mirada. Produce un bizqueo, un estrabismo, y queda lo lineal como un extremo horizonte que presiona los cuerpos. El dibujo se me viene con todo su cuerpo y su posesión de líneas y sombras. Además, sirve de antesala a una espacialidad conjurada. Tacha e impronta que resuenan en forma de cabezas risibles. Imposible de contener a la sombra, la silueta de un rostro particular le permite ser arrasado por la inmanencia del blanco. La vacuidad acrecienta la diferencia con respecto a la ilustración, pues nada quiere representar sino en lo que a celebración acontece. Esta es la tachadura del dibujo, esta es su fragilidad e impronta.

\section{Referencias}

Berger, Jhon. (2011) Sobre el dibujo. Barcelona: Gustavo Gili 
Blanchot. Maurice. (1992). El espacio literario.

Barcelona: Paidós.

Deleuze, Gilles (2002). Francis Bacon. Lógica

de la sensación. Madrid: Arena Libros.

Derrida. Jacques (1994). Las artes del espacio.

Entrevista de Peter Brunette y David Wills realizada el 28 de abril de 1990 en Laguna Beach. California.

Deconstruction and Visual Arts. Cambridge University

Press.

(2001). La Verdad en Pintura.

Buenos Aires:Paidós

Erber, W. (1992). Miró. Colonia: Taschen.

Lyotard, Jean-Francois. (1998). Lo inhumano.

Charlas sobre el tiempo. Buenos Aires: Manantial.

Paz, Octavio (2004). Los privilegios de la vista I. Arte moderno universal. México D.F.: Círculo de Lectores, Fondo de Cultura Económica. 